\title{
A Study about Amendment of Safety Control of Computed Tomography
}

\author{
Kyotae Kim*, Yeji Heo**, Kyungmin $\mathrm{Oh}^{* *}$, Sicheul Noh ${ }^{* * *}$, Sangsik Kang ${ }^{* * *}$, Sanghee Nam ${ }^{* *}$, Jikoon Park ${ }^{* * *}$ \\ Dept. of Hybrid Medicine and Science, Inje University ${ }^{*}$, Dept. of Biomedical Engineering, Inje University ${ }^{* *}$, \\ Dept. of Radiological Science, International University of Korea ${ }^{* * *}$

\section{전산화단층찰영용장치의 안전관리 개정에 관한 연구} \\ 김교태*, 허예지**, 오경민 ${ }^{* *}$, 노시철***, 강상식***, 남상희 ${ }^{* *}$, 박지군*** \\ 인제대학교 융합의과학*, 인제대학교 의용공학과**, 한국국제대학교 방사선학과***
}

\begin{abstract}
Diagnostic imaging systems play a critical role in obtaining anatomical images, which increases the frequency of inspection all over the world. However the likelihood that patients are exposed to relatively high radiation dose increases, which may lead to an increase of patient dose due to unnecessary radiation exposure unless appropriate management is accompanied. Thus the revised edition of IEC 60601-2-44 which is constancy tests for CT equipment which is designated as special medical equipment and is subject to safety management was studied. The results suggested the 3rd has been revised rationally in order to overcome the limitations in the 2nd by adopting clear and enhanced references, which implies the replacement of IEC 60601-2-44 2nd edition with IEC 60601-2-44 3rd will prevent the patients from the harm from improper medical equipment.
\end{abstract}

Key Words: Computed Tomography, Quality Control, International Electro-technical Committee

\section{요 약}

본 연구에서는 해부학적 영상 획득에 중추적인 역할을 담당함에 따라 전 세계적으로 검사빈도가 증가하고 있다. 하 지만, 환자가 받는 방사선량이 상대적으로 높아 적절한 관리가 이루어지지 않으면 과도하거나 불필요한 방사선 피폭으 로 환자선량을 증가시킬 수 있다. 이를 위해 특수의료장비로 지정하여 안전관리를 시행하고 있는 전산화 단층촬영용 장치의 항구성 시험 IEC 60601-2-44의 개정판에 대하여 문헌 조사하였다. 그리고 비교 및 분석을 통하여 새로운 요 구 사항에 대하여 알아보고자 하였다. 문헌 조사 결과 개정된 3 판 $(3 \mathrm{rd} \mathrm{Ed)에서는} \mathrm{명확하고} \mathrm{강화된} \mathrm{기준값을} \mathrm{적용하고}$ 있고, 2판에서(2nd Ed)의 한계점을 해결하기 위하여 합리적으로 개정되었다. 그러므로 현재 국내에서 적용하고 있는 IEC 60601-2-44 2판을 개정된 IEC 60601-2-44 3판으로 적용한다면 부적합한 의료장비로 인한 환자의 위해를 막 을 수 있을 것으로 사료된다.

중심단어: 전산화 단층촬영용 장치, 정도관리, 국제 전기기술 위원회

\section{I. 서 론}

전산화 단층촬영용 장치는 해부학적 영상 획득에
중추적인 역할을 담당함에 따라 전 세계적으로 검사 빈도가 증가하고 있으나 ${ }^{[1]}$, 환자가 받는 방사선량이 상대적으로 높아 진단에 따른 이익과 위험이 적절하 게 균형을 이룰 필요가 있다 ${ }^{[2]}$. 또한 적절한 관리가 이 
루어지지 않으면 과도하거나 불필요한 방사선 피폭으 로 환자선량을 증가시킬 수 있어 ${ }^{[3]}$, 국제적으로 전산 화 단층촬영용 장치는 특수의료장비로 지정하여 안전 관리를 시행하고 있다. 이러한 안전관리의 규제는 국 제전기기술 위원회(International Electrotechnical Committee, IEC)에서 항구성 시험 IEC 60601-2-44와 일 관성 시험 IEC 61223-2-6을 규격을 발간하여 따르도록 권고하고 있다 ${ }^{[4],[5]}$. 최근 $\mathrm{IEC}$ 에서는 의료기기국제규격 이 기술발전에 미흡하다고 판단하여 전자의료기기에 대한 공통규격 IEC 60601-1 3판을 발간하였다. 국내의 경우 산업체의 국제경쟁력을 확보하고 의료기기의 안 전성 확보를 통한 국민보건을 위하여 3판에 따른 시험 기준 및 기준규격을 적용해야하지만, 3 판에 대한 정부 및 시험검사시관의 준비가 부족하고, 제조업체에 부담 이 되는 새로운 요구사항이 추가되어, 전산화 단층촬 영용 장치의 항구성 시험 규제 시 IEC 60601-2-44 2판 을 적용하고 있는 실정이다 ${ }^{[6],[7] . ~}$

이에 본 연구에서는 전산화 단층촬영용 장치 항구 성 시험에 관한 개정 사항을 파악하기 위하여 IEC 60601-2-44 2판과 IEC 60601-2-44 3판을 비교 및 분석하 여 개선 사항 및 추가 사항에 대하여 고찰하였다.

\section{II. 연구방법}

전산화 단층촬영용 장치의 항구성 시험은 국제 전 기기술 위원회에서 발간하는 문헌 중 개별 규격으로 60601 시리즈에 포함되어 있다. 본 연구에서는 전산화 단층촬영용 장치의 항구성 시험에 대한 검사 항목 및 기준을 조사하기 위하여 현재 적용되고 있는 2판은 한 국 표준 협회에서 규정하고 있는 C IEC 60601-2-44의 ‘의료용 전기 기기-제 2-44부 : 전산화 단층 $\mathrm{X}$ 선 촬영 장치의 안전에 관한 개별 요구 사항을 문헌 조사하였 다 ${ }^{[7]}$. 또한 국가표준인증종합정보센터에서 제공하는 한국산업표준(KS) 중 C IEC 60601-2-44 3판에 대한 문 헌과 비교를 통하여 새로운 요구 사항에 대하여 파악 하고 ${ }^{[8]}$, 삭제 항목 및 추가 항목 그리고 개정 사항으로 분류하여 분석하였다.

\section{III. 결과 및 고찰}

Table 1. Check list Comparison of IEC 60601-2-44 2nd Ed. and 3rd Ed.

\begin{tabular}{|c|c|c|}
\hline $\begin{array}{l}\text { Version } \\
\text { Check list }\end{array}$ & 2nd Ed & $3 r d \mathrm{Ed}$ \\
\hline 전원 & 전원 & 전원 \\
\hline $\begin{array}{c}\text { 전압 } \\
\text { or 에너지 제한 }\end{array}$ & 전압 or 에너지 제한 & 전압 or 에너지 제한 \\
\hline \multirow{2}{*}{$\begin{array}{c}\text { 외함 및 보호 } \\
\text { 덮개 }\end{array}$} & 외장 및 보호 커버 & - \\
\hline & 보호 접지 & - \\
\hline $\begin{array}{l}\text { 연속 누설 전류 } \\
\text { 및 환자 측정 } \\
\text { 전류 }\end{array}$ & $\begin{array}{l}\text { 연속 누설 전류 } \\
\text { 및 환자 측정 전류 }\end{array}$ & $\begin{array}{c}\text { 연속 누설 전류 } \\
\text { 및 환자 측정 전류 }\end{array}$ \\
\hline \multirow{5}{*}{ 가동부 } & 갠트리의 경사 & 갠트리의 경사 \\
\hline & $\begin{array}{l}\text { 환자 지지기의 } \\
\text { 직선운동 } \\
\end{array}$ & $\begin{array}{c}\text { 환자 지지대와 } \\
\text { 갠트리의 직선 동작 }\end{array}$ \\
\hline & - & 의도하지 않은 동작 \\
\hline & - & 의도하지 않은 정전 \\
\hline & 모터 구동 비상 & - \\
\hline 공압 및 수압 & $\begin{array}{c}\text { CT 스캐너의 } \\
\text { 압력식 구동부에서의 } \\
\text { 압력 변동 }\end{array}$ & - \\
\hline 전기기 적합성 & 전기기 적합성 & - \\
\hline \multirow{4}{*}{$\begin{array}{c}\text { 동작 데이터의 } \\
\text { 정확성 }\end{array}$} & 방사선 출력의 정확성 & 방사선 출력의 정확성 \\
\hline & 기록된 검사 & 기록된 검사 \\
\hline & 데이터의 정확성 & 데이터의 정확성 \\
\hline & 표시 생략 & - \\
\hline \multirow{3}{*}{ X선 방사 } & $\mathrm{X}$ 선 방사의 비상 종료 & $\mathrm{X}$ 선의 비상 정지 \\
\hline & 가동 상태 표시 & 동작 대기상태의 표시 \\
\hline & 방사선 출력 제한 & 방사선 출력의 제어 \\
\hline \multirow{14}{*}{ X선 방사 } & 외부 인터로크 접속 & $\begin{array}{l}\text { 외부 인터록 } \\
\text { 장치의 연결 }\end{array}$ \\
\hline & - & 충전모드 인터록 장치 \\
\hline & 선량 분포 & 선량 분포 진술 \\
\hline & 시각적 표시 & 시각적 표시 \\
\hline & 용적 (CTDIVol) & $\begin{array}{c}\text { CTDIVol 와 DLP의 } \\
\text { 표시 및 기록 }\end{array}$ \\
\hline & 빔-온 상태 표시기 & - \\
\hline & 방사선 선질 & 방사선 선질 \\
\hline & $\mathrm{X}$ 선 장치에서 총여과 & - \\
\hline & - & 필터 특징의 표시 \\
\hline & X선 빔의 감쇠 & - \\
\hline & $\begin{array}{l}\text { X선 빔 범위의 } \\
\text { 제한 및 표시 }\end{array}$ & - \\
\hline & $\begin{array}{c}\text { 단층 촬영 단면의 } \\
\text { 표시 및 위치 }\end{array}$ & $\begin{array}{l}\text { 단층 단면의 } \\
\text { 지시와 위치 }\end{array}$ \\
\hline & - & $\begin{array}{c}\text { 잔류 방사선에 } \\
\text { 대한 방어 }\end{array}$ \\
\hline & 부속 문서의 기술 & 부속 문서에 진술 \\
\hline
\end{tabular}

개정된 공통규격 60601-1 3판은 의료용 전기기기 안 전성, 필수성능 공통 적용 규격으로 세부 규격으로는 보조규격, 성능규격, 개별규격으로 구분할 수 있다. 이 중 보조규격은 공통규격의 특정 시험 항목에 적용하 
는 규격으로 60601-1-n으로 표기하고, 개별 규격은 크 게 60601 시리즈와 80601 시리즈로 구분된다. 60601 시 리즈는 공통규격 외 품목별 요구 사항에 적용하는 규 격으로 60601-2-n으로 표기한다.

세부 규격인 전산화 단층촬영용 장치 항구성 시험 은 개별규격으로 IEC 60601-2-44이며, 2009년도에 IEC 에서 3판을 발간하였다. 이러한 IEC 60601-2-44 3판의 개정 사항에 대한 평가 항목을 Table 1에 나타내었다. 또한 평가항목을 더 정확히 분석하기 위하여 삭제된 항목 및 추가된 항목 그리고 세부 내용이 개정된 항목 으로 구분하여 비교하였다. 분석 결과 총 10 개의 항목 이 삭제되었고, 추가된 항목은 총 6 개로 확인되었다. 이는 안전성에 대해서만 요구하였던 2판과는 달리, 3 판에서는 안정성 및 필수성능(Essential Performance)을 고려하고 있다. 필수성능이란 허용할 수 없는 위험 (Unacceptable RISK)으로부터 자유롭게 될 수 있는데 요구되는 성능으로 추가된 항목 중에서 의도하지 않 은 동작 또는 정전에, 잔류 방사선에 대한 방어 등을 의미한다. 이 외에도 많은 항목들이 개정되었으며, 개 정 사항은 크게 세부 내용이 개정된 항목 및 적합 여 부 확인 방법이 개정된 항목, 세부 내용 및 적합 여부 확인이 모두 개정된 항목 3 개로 구분할 수 있다. 삭제 된 항목 및 추가된 항목에 대하여 비교, 분석 결과를 Table 2에 나타내었다.

Table 2. Check list of Withdrawn And Additional

\begin{tabular}{ccc}
\hline \multirow{2}{*}{ No. } & \multicolumn{2}{c}{ Amendments } \\
\cline { 2 - 3 } & Withdrawn Check list & Additional Check l ist \\
\hline 1 & 외장 및 보호 커버 & 의도하지 않은 동작 \\
\hline 2 & 보호접지 & 의도하지 않은 정전 \\
\hline 3 & 모터 구동 비상 & 충전모드 인터록 장치 \\
\hline 4 & $\begin{array}{c}\text { CT 스캐너의 압력식 } \\
\text { 구동부에서의 압력 변동 }\end{array}$ & 필터 특징의 표시 \\
\hline 5 & 빔-온 상태 표시기 & 잔류 방사선에 대한 방어 \\
\hline 6 & X선 장치에서 총여과 & CTDIVol와 DLP의 표시 및 \\
\cline { 1 - 2 } 기록 \\
\hline 8 & X선 빔 범위의 제한 및 표시 & \\
\hline 9 & X선 빔의 감쇠 & \\
\hline 10 & 전기기 적합성 & \\
\hline \multicolumn{3}{c}{ 표시 생략 } \\
\hline
\end{tabular}

세부 내용의 비교 및 분석 결과 개정된 항목 중 추 가된 항목으로는 연속 누설 전류 및 환자 측정 전류,
$\mathrm{X}$ 선의 비상 정지, 방사선 출력의 제어, 선량 분포로 총 5 가지이고, 부속 문서 진술에 대한 항목은 세부 내용 이 대체되었으며, 단층 단면의 지시와 위치에 대한 항 목은 세부 내용이 추가 및 대체되었다. 이러한 비교 결과를 Table 3에 나타내었다.

Table 3. Amendments of Check list

\begin{tabular}{|c|c|c|c|}
\hline \multirow[b]{2}{*}{ No. } & \multicolumn{3}{|c|}{ Amendments } \\
\hline & Details & $\begin{array}{c}\text { fitness } \\
\text { possibility }\end{array}$ & $\begin{array}{c}\text { Details \& } \\
\text { fitness } \\
\text { possibility }\end{array}$ \\
\hline 1 & $\begin{array}{c}\text { 연속 누설 전류 } \\
\text { 및 } \\
\text { 환자 측정 전류 }\end{array}$ & 전원 & $\begin{array}{c}\text { 전압 } \\
\text { or 에너지 제한 }\end{array}$ \\
\hline 2 & $\begin{array}{c}\text { X선의 } \\
\text { 비상 정지 }\end{array}$ & 갠트리의 경사 & $\begin{array}{c}\text { 환자 지지대와 } \\
\text { 갠트리의 } \\
\text { 직선 동작 }\end{array}$ \\
\hline 3 & $\begin{array}{c}\text { 방사선 } \\
\text { 출력의 제어 }\end{array}$ & $\begin{array}{c}\text { 동작 대기 } \\
\text { 상태의 표시 }\end{array}$ & \\
\hline 4 & 선량 분포 & $\begin{array}{l}\text { 외부 인터록 } \\
\text { 장치의 연결 }\end{array}$ & \\
\hline 5 & 방사선 선질 & 시각적 표시 & \\
\hline 6 & $\begin{array}{l}\text { 단층 단면의 } \\
\text { 지시와 위치 }\end{array}$ & $\begin{array}{c}\text { 방사선 출력의 } \\
\text { 정확성 }\end{array}$ & \\
\hline 7 & $\begin{array}{c}\text { 부속 문서에 } \\
\text { 진술 }\end{array}$ & $\begin{array}{c}\text { 기록의 검사 } \\
\text { 데이터의 정확성 }\end{array}$ & \\
\hline
\end{tabular}

세부 내용의 개정된 항목 중 추가된 내용을 Table 4 에 나타내었다. 그리고 대체된 내용을 Table 5 에 나타 내었다. 추가 및 대체된 내용은 2 판에서 제시하고 있 는 기준값(Stathard Value) 보다 엄격하고 명확한 기준 값을 제시하고 있다. 추가된 항목 중 연속 누설 전류 및 환자 측정 전류에 관한 항목에서는 기준값을 제시 하지 않았으나, 3 판에서는 각 상태와 경우에서의 기준 값을 명확하게 제시하고 있다. $\mathrm{X}$ 선의 비상 정지에 관 한 항목은 0.5 초 이내에 차단되어야 한다는 기준값이 제시되었으며, 방사선 출력의 제어에 관한 항목에서는 자동노출제어(Automatic Exposure Controlor, AEC) 기능 에 대한 규정이 추가되었다. 또한 대체된 항목 중 단 층 단면의 지시와 위치에 관한 항목에서 2 판에서는 한 번에 1 개 이상의 단층 촬영 단면 획득 시를 규정하였 으나, 한 번에 2개 이상의 단층 단면을 얻는 경우에 광 조사야의 위치를 기술하는 것으로 개정되었고, 부속 문서 진술에 관한 항목은 양쪽 방향에서 수행되던 규 정을 수직면과 회전축에 수직한 면의 경우로 제시되 었다. 
적합 여부 확인 방법의 개정된 항목 분석 결과, 전 원, 갠트리의 경사, 시각적 표시, 방사선 출력의 정확 성, 기록의 검사 데이터의 정확성에 대한 평가항목은 2판에서는 육안 검사로 규정되어 있다. 이는 객관적인 평가가 아닌 주관적인 평가기준으로서 평가자에 따른 평가결과의 차이가 발생할 수 있는 한계점을 가진다. 하지만, 3판에서는 부속 문서 검사, 기능 시험으로 판 정하는 것으로 개정됨에 따라 더 객관적인 평가가 가
능할 것으로 사료된다. 또한 동작 대기 상태의 표시, 외부 인터록 장치의 연결에 대한 평가항목은 2 판에서 는 검사 및 적절한 기능 시험으로 확인하는 것으로 규 정되어 있었으나, 3 판에서는 육안 검사, 적절한 기능 시험을 통해 판정 하는 것으로 개정되었다. 세부 내용 및 적합 여부 확인에 대하여 개정된 항목들의 비교 및 분석 결과를 Table 6에 나타내었다.

Table 4. Check list of Amendments for Additional Details

\begin{tabular}{|c|c|}
\hline Check list & Details \\
\hline & - 접지 누설 전류의 허용치는 정상상태에서 $5 \mathrm{~mA}$ 이고 단일 고장상태에서 $10 \mathrm{~mA}$ \\
\hline $\begin{array}{c}\text { 연속 누설 전류 } \\
\text { 및 }\end{array}$ & $\begin{array}{l}\text { - 영구 설치된 CT 스캐너 및 그 중간 조립품이 이 CT 스캐너에 만 전원을 공급하는 전원 회로에 연결된 경우, 정상 및 단일 고장 } \\
\text { 상태 시 접지누설전류는 } 10 \mathrm{~mA} \text { 를 초과하면 안 됨 }\end{array}$ \\
\hline 환자 측정 전류 & $\begin{array}{l}\text { - 영구 설치된 CT 스캐너의 경우,파형 및 주파수와 관계없이 비주파수 가중장치로 측정했을 때 정상상태 및 단일 고장 상태에서 } \\
\text { 접지누설전류는 } 20 \mathrm{~mA} \text { 를 초과하면 안됨 }\end{array}$ \\
\hline $\begin{array}{c}\text { X선의 } \\
\text { 비상 정지 }\end{array}$ & $\begin{array}{l}\text { - 수단은 환자 지지대 또는 그 근처, 그리고 방사선을 조작하는 제어판 또는 그 근처에 고정 배선회로 설치 } \\
\text { - 부하는 비상 정지 시 } 0.5 \text { 초 이내에 차단 }\end{array}$ \\
\hline $\begin{array}{l}\text { 방사선 } \\
\text { 출력의 제어 }\end{array}$ & $\begin{array}{l}\text { - 각 CT 스캐너에는 CT 동작조건의 수동선택 대신 사용할 수 있는 동작모드의 형태로 자동노출제어 기능이 있어야 함 } \\
\text { - 제조자는 자동 노출제어에 대한 정보를 사용설명서에 명시함 또한 자동 노출제어의 성능표준에 대한 더 상세한 정보를 부속문 } \\
\text { 서에 명시함 }\end{array}$ \\
\hline 선량 분포 & - 그래픽 표현에는 적어도 선량 분포의 $1 / 10$ 최대값에서 적어도 최대폭으로 확장되는 $\mathrm{z}$ 방향상의 범위가 포함되어야함. \\
\hline 방사선 선질 & $\begin{array}{l}\text { - 선택 가능한 각 각의 필터에 대한 시스템의 반가층은 부속문서에 X선관 전압의 최소값, 최고값, 중간값으로 명시함 } \\
\text { - 성형필터가 포함되어 있는 CT 스캐너의 경우에는 단층면 중앙의 시스템 등각점에서 방사선 선질 측정하고 그 결과값을 부속문 } \\
\text { 서에 명시함 }\end{array}$ \\
\hline $\begin{array}{l}\text { 단층 단면의 } \\
\text { 지시와 위치 }\end{array}$ & $\begin{array}{l}\text { - 나선형 주사의 경우 ,방사선 조사된 총 체적의 } z \text { 축 상 범위가 미리보기 영상에 표시되어야 한다. 부하의 시작과 정지에 해당 } \\
\text { 하는 } 2 \text { 개의 기준선이 표시되어야 한다. 각 선은 사용한 빔 콜리메이션에 대한 공기 중 선량분포의 FWHM의 바깞쪽 모서리에 해당 } \\
\text { 하야여 함 }\end{array}$ \\
\hline
\end{tabular}

Table 5. Check list of Amendments for Alternative Details

\begin{tabular}{|c|c|c|}
\hline \multirow{2}{*}{ Check I ist } & \multicolumn{2}{|r|}{ Details } \\
\hline & 2nd Ed & $3 r d E d$ \\
\hline 다츠 다며이 & 한 번에 1 개 이상의 단층 촬영 단면이 얻어 & 한번에 2개 이상의 단층 단면을 얻는 경우에는 단층 단면에 대한 광 조사야의 \\
\hline $\begin{array}{l}\text { 잔시와 완한긔 }\end{array}$ & $\begin{array}{l}\text { 진다면, 부속 문서에 단층 촬영 단면에 대한 } \\
\text { 광 조사장의 위치를 기술하여야 함. }\end{array}$ & $\begin{array}{l}\text { 위치를 부속 문서에 명시하여야 한다. 시상 및 관상 위치를 표기하는 광 조사 } \\
\text { 야에 대한 등각점 위치의 정확도를 부속문서에 명시하여야 함 }\end{array}$ \\
\hline $\begin{array}{c}\text { 부속 문서에 } \\
\text { 진술 }\end{array}$ & 측정은 양쪽 방향에서 적어도 $50 \mathrm{~cm}$ 마다 수행 & $\begin{array}{l}\text { 수직면의 경우, 회전축에 평행한 면은 길이가 적어도 } 3 \mathrm{~m} \text { (그 중심이 주사면에 } \\
\text { 있음)이며 환자 지지물 영역을 포함하는데 필요한 만큼 확장된다. 회전축에 } \\
\text { 수직한 면은 회전축 위치로부터 적어도 } 0.5 \mathrm{~m} \text { 밑, } 1.5 \mathrm{~m} \text { 위까지 확장되어야 함 }\end{array}$ \\
\hline
\end{tabular}

Table 6. Check list of Amendments for Details and fitness possibility

\begin{tabular}{|c|c|c|c|}
\hline \multirow{2}{*}{\multicolumn{2}{|c|}{ Check I ist }} & \multicolumn{2}{|r|}{ Details } \\
\hline & & 2nd Ed & 3rd Ed \\
\hline \multirow{2}{*}{$\begin{array}{c}\text { 전압 or 에너지 } \\
\text { 제한 }\end{array}$} & 세부 내용 & \multirow[t]{2}{*}{ 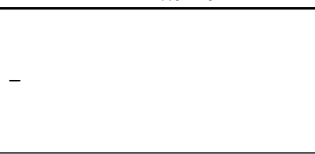 } & $\begin{array}{l}\text { 환자 주사와 관련된 정상 사용 시 } \mathrm{X} \text { 선관 장치의 공칭 } \mathrm{X} \text { 선관 전압보다 } \\
\text { 더 높은 전압이 발생하지 않도록 설계 }\end{array}$ \\
\hline & 적합 여부 확인 & & $\begin{array}{l}\text { 해당 부품에 대한 제조자 데이터를 검사, 의료 기기를 점검, 그리고 } \\
\text { 필요한 경우 기능 시험을 실시하여 판정 }\end{array}$ \\
\hline \multirow[t]{2}{*}{$\begin{array}{l}\text { 환자 지지대 및 } \\
\text { 갠트리의 직선 } \\
\text { 동작 }\end{array}$} & 세부 내용 & $\begin{array}{l}\text { 비상 정지 제어기가 작동 시, } \\
\text { 환자 지지기는 } 10 \mathrm{~mm} \text { 이내 }\end{array}$ & $\begin{array}{l}\text { a) 환자 지지대 움직임 (위/아래/옆)은 비상 정지 장치가 작동한 후 } \\
10 \mathrm{~mm} \text { 이내에 정지하여야 함 } \\
\text { b) Z 방향 운동은 비상 정지 장치가 작동한 후 } 25 \mathrm{~mm} \text { 이내에 } \\
\text { 정지하여야 함 }\end{array}$ \\
\hline & 적합 여부 확인 & 육안 검사 & 기능 시험으로 판정 \\
\hline
\end{tabular}


분석 결과, 3판이 적용될 경우 새로운 요구사항이 추가되어 제조업체에 부담이 될 것으로 사료되나, 2판 에 비하여 명확하고 강화된 기준값 및 객관적인 평가 방법 그리고 필수성능의 고려와 같은 장점을 통하여 의료기기의 안전성 확보가 가능할 것으로 사료된다. 또한 국외의 경우 3 판의 적용을 강제적으로 시행하고 있는 현 시점에서 국내 산업체의 국제경쟁력을 갖추 기 위해서는 빠른 시일 내에 3판에 따른 시험기준 및 기준규격을 적용하여야 할 것으로 사료된다.

\section{$\mathrm{IV}$. 결 론}

본 연구에서는 전 세계적으로 검사빈도가 증가하고 있으나, 환자가 받는 방사선량이 상대적으로 높아 적 절한 관리가 이루어지지 않으면 과도하거나 불필요한 방사선 피폭으로 환자선량을 증가시킬 수 있어, 특수 의료장비로 지정하여 안전관리를 시행하고 있는 전산 화 단층촬영용 장치의 항구성 시험 IEC 60601-2-44의 개정판에 대하여 문헌 조사하였고, 문헌을 비교 및 분 석하여 새로운 요구 사항에 대하여 알아보고자 하였 다 ${ }^{[8],[9]}$. 비교 분석 결과, 세계적인 선량 저감화 추세에 발맞추어 사용자의 의도하지 않은 사건(Event)에 대하 여 고려를 하고 있고, 선량의 방어 및 표시를 의무화 하는 노력을 기울이고 있다. 또한 많은 개정된 항목들 은 2판에 비해 명확하고 강화된 기준값(Standard Value) 을 적용하고 있고, 한계점을 해결하기 위하여 합리적 으로 개정하였다. 이러한 분석 결과 개정된 IEC 60601-2-44 3판의 시험기준 및 기준규격을 적용하여 합 리적으로 관리한다면, 산업체의 국제경쟁력을 확보할 수 있을 것으로 사료되고, 의료기기의 안전성 확보를 통해 부적합한 의료장비로 인한 환자에 대한 위해를 최소화 할 수 있고 국민보건에 긍정적인 영향을 미칠 수 있을 것으로 사료된다.

\section{감사의 글}

본 연구는 교육과학기술부와 한국연구재단의 지역 혁신인력양성사업으로 수행된 연구결과임.

본 연구는 산업통상자원부 및 한국산업기술진흥원 의 지역연고산업육성사업의 연구결과로 수행되었음 (R0002116).

\section{참고문헌}

[1] Mettler FA, Jr., Wiest PW, Locken JA, Kelsey CA, "CT scanning: patterns of use ath dose", J Radiol Prot, Vol. 20, pp. 353-359, 2000.

[2] Legitimacy and Optimization Guidelines of Computed Tomography Radiology, Korea Food \& Drug Administration, Radiation safety management series No. 28, 2012.

[3] Kalra M.K., Maher M.M., Toth T.L., et. al., "Strategies for CT radiation dose optimization", Radiology, Vol. 230, pp. 619-628, 2004.

[4] Evaluation ath routine testing in medical imaging departments - Part 2-6 : Constancy tests-X-ray equipment for computed tomography; IEC 61223-2-6:1994, International Electro-technical Committee; IEC, 1994.

[5] Medical electrical equipment - Part 2 - 44 : Particular requirements for the basic safety ath essential performance of X-ray equipment for computed tomography; IEC 60601-2-44:2001, International Electro-technical Committee; IEC, 2001.

[6] Korea Testing Laboratory, "A study on the mandatory application plan for the third edition of IEC 60601 standards series(General Standard, Collateral Standards, Particular Standards)", National Institute of Food and Drug Safety Evaluation, 2011.

[7] K.T. Kim etc, "A study on the improvement of evaluation methods and standards for simulation evaluation of computed tomography", J. Korean. soc. radiol, Vol. 7, pp. 339-345, 2013

[8] Medical electrical equipment - Part 2 - 44 : Particular requirements for the safety of X-ray equipment for computed tomography, KS C IEC 60601-2-44:2005, Korean Standards Association, 2005.

[9] "Medical electrical equipment - Part 2 - 44 : Particular requirements for the basic safety and essential performance of X-ray equipment for computed tomography, KS C IEC 60601-2-44:2011", Korean Standards Association , 2011. 